\title{
DIFFERENCES IN THE VALUE OF BLOOD UREA NITROGEN AND CREATININE SERUM IN CERVICAL CANCER SQUAMOUS CELL STADIUM IIB-IIIB BEFORE AND AFTER CHEMOTHERAPY PACLITAXEL CISPLATIN FOR SIX CYCLES IN SANGLAH GENERAL HOSPITAL DENPASAR, BALI
}

\author{
NOVIYANI ${ }^{1 *}$, INDRAYATHI PA ${ }^{2}$, THABRANY ${ }^{3}$, ANDRIJONO ${ }^{4}$, BUDIANA NG ${ }^{5}$ \\ ${ }^{1}$ Department of Pharmacy, Faculty of Mathematics and Sciences, Udayana University, Bali, Indonesia. ${ }^{2}$ Department of Public Health, \\ Faculty of Medicine, Udayana University, Bali, Indonesia. ${ }^{3}$ Center for Health Economics and Policy Studies, Indonesia University, Jakarta, \\ Indonesia. ${ }^{4}$ Department of Obstetrics and Gynecology, Faculty of Medicine, Indonesia University, Jakarta, Indonesia. ${ }^{5}$ Department of \\ Obstetrics and Gynecology, Faculty of Medicine, Udayana University, Bali, Indonesia. Email: rini.noviyani@gmail.com
}

Received: 20 October 2016, Revised and Accepted: 01 November 2016

Objective: The combination of paclitaxel-cisplatin regimen is one of the chemotherapy regimens used at Sanglah General Hospital, Denpasar. Cisplatin is a potent chemotherapeutic agent, but the nephrotoxic effects of cisplatin reported that research is needed to see the toxic effect on the kidneys before and after 6 series of paclitaxel-cisplatin chemotherapy. Toxicity assessment of the chemotherapy can be observed by evaluating kidney function from monitoring both blood urea nitrogen (BUN) and creatinine serum value.

Methods: The research was conducted as an observational study using a prospective cohort method. The research was conducted from January 2016 to June 2016. Patients' follow-up was conducted from the first until the last series of chemotherapy. The data were statistically analyzed with STATA version 14 with paired t-test when the data were normally distributed or the data were analyzed with Wilcoxon test when they were not normally distributed.

Results: A total of seven patients were evaluated with both their BUN and creatinine serum values during six series of chemotherapy. Statistically, the BUN and creatinine serum values before the first and after the last paclitaxel-cisplatin chemotherapy series are not statistically significantly different ( $p>0.05$ ).

Conclusion: There are no significant changes of both BUN and creatinine serum values before the first and after the last paclitaxel-cisplatin chemotherapy series in patients with stadium IIB-IIIB squamous cell cervical cancer. Research with larger sample size is essential to provide optimal information for other health-care professionals.

Keywords: Cervical cancer, Paclitaxel-cisplatin, Creatinine serum, Blood urea nitrogen.

(c) 2017 The Authors. Published by Innovare Academic Sciences Pvt Ltd. This is an open access article under the CC BY license (http://creativecommons. org/licenses/by/4. 0/) DOI: http://dx.doi.org/10.22159/ajpcr.2017.v10i2.15788

\section{INTRODUCTION}

Cervical cancer is the second most prominent cancer in the world. Data based on preliminary studies conducted by researchers at Sanglah General Hospital (GH) in December 2015 show that there were 2157 cervical cancer patients in 2013 and this number increased by $61 \%$ within a year to 3473 cervical cancer patients in 2014. This number keeps on increasing annually, in which in 2015, the number of cervical cancer patients at Sanglah GH was recorded at 4797, with the most gynecologic ferocity indicated as squamous cell cervical cancer.

One therapeutic procedure for cervical cancer is chemotherapy. Sixcyclic chemotherapy will provide better result toward the cancer victims than three-cyclic chemotherapy. However, the former would undeniably result in higher toxicity level compared to the latter one. This is in concord to Colleani et al's. (2002) research findings, in which breast cancer patients who went through less chemotherapy procedures could significantly reduce the toxic risk. As a result, there needs to be a study about six-cyclic chemotherapy toxic implication toward cervical cancer patients [1]

Cisplatin is the nephrotoxic chemotherapy agent. Platinum content in cisplatin has the role of inducing nephrotoxicity due to glomerular damage [2]. Nephrotoxic effect by cisplatin agent could be monitored from the value of blood urea nitrogen (BUN) and creatinine serum used as the indicator of the patients' kidney function. The increase of BUN level and creatinine serum in patients could be utilized to assess the degree of kidney dysfunction as the side effect of chemotherapy [3]. Thus, the focus of this research would be to determine whether or not there is a toxicity difference in patients' kidney function indicated by creatinine serum and BUN before the first chemotherapy series and after the sixth chemotherapy series.

\section{METHODS}

The research was conducted in Sanglah GH, Denpasar, after acquiring ethical clearance permission from the Ethical Research Committee of Medical Faculty, Udayana University. It is an observational research utilizing case study method at Obstetrics and Gynecology Clinics, Sanglah GH, Denpasar, Bali. This method was carried out by following up patients beginning from the first chemotherapy to the sixth chemotherapy cycle. The data were taken from before and after chemotherapy Cycles I and VI. Selection of patients was based on the following criteria: New patients with squamous cell cervical cancer stadium IIB-IIIB; patients who agree to follow-up research by filling informed consent; clinical conditions and laboratory results that fulfill the requirements to get chemotherapy; and patients who could go through the entire range of chemotherapy Cycles I-III. Exclusion criteria of the research were patients whose progress could not be followed up for reasons such as death, financial problems, and loss of contact (lost to follow-up).

The data of creatinine serum and BUN were measured before chemotherapy Cycle I and after chemotherapy Cycle VI. Furthermore, all data obtained have undergone a normality test by first using Shapiro- 
Wilk test. If the data were normal, paired t-test will be tested. If the data were not normal, the data would be analyzed by Wilcoxon test. The significantly different impact on creatinine serum and BUN in patients was characterized by a value of $\mathrm{p}<0.05$.

\section{RESULTS}

Within the period of January until June 2016, there were seven patients acquired as the research patients. The limited number of research patients was due to time limitation and the limited number of patients who fulfilled both the inclusion and exclusion criteria as well as the ones who could complete the six chemotherapy series.

\section{Patients' characteristics}

The seven research patients' characteristics were categorized into age, marital age, marital status, educational level, occupational status, area of origin, stadium of disease, and insurance status (Table 1).

Table 1: Patients characteristics

\begin{tabular}{|c|c|}
\hline Patients' characteristics & Quantity N=7 (\%) \\
\hline \multicolumn{2}{|l|}{ Age } \\
\hline $26-35$ & $1(14.28)$ \\
\hline $36-45$ & $3(42.86)$ \\
\hline $46-55$ & $2(28.57)$ \\
\hline $56-65$ & $1(14.28)$ \\
\hline \multicolumn{2}{|l|}{ Marital age } \\
\hline $15-20$ & $3(42.86)$ \\
\hline $20-25$ & $4(57.12)$ \\
\hline$>25$ & $0(0)$ \\
\hline \multicolumn{2}{|l|}{ Marital status } \\
\hline Married & $7(100)$ \\
\hline Not married & $0(0)$ \\
\hline \multicolumn{2}{|l|}{ Educational level } \\
\hline No formal education & $1(14.28)$ \\
\hline Elementary & $3(42.86)$ \\
\hline Middle school & $2(28.57)$ \\
\hline High school & $1(14.28)$ \\
\hline \multicolumn{2}{|l|}{ Occupational status } \\
\hline Private employee & $2(28.57)$ \\
\hline Farmer & $1(14.28)$ \\
\hline Housemaid & $1(14.28)$ \\
\hline Homemaker & $1(14.28)$ \\
\hline Merchant & $2(28.57)$ \\
\hline \multicolumn{2}{|l|}{ Area of origin } \\
\hline Bali & $3(42.86)$ \\
\hline East Lombok, NTB & $2(28.57)$ \\
\hline Sulawesi & $1(14.28)$ \\
\hline Banyuwangi, East Java & $1(14.28)$ \\
\hline \multicolumn{2}{|l|}{ Stadium of disease } \\
\hline IIB & $0(0)$ \\
\hline IIIB & $7(100)$ \\
\hline \multicolumn{2}{|l|}{ Insurance status } \\
\hline BPJS* Umum" & $5\left(71.43^{\wedge}\right)$ \\
\hline BPJS Askes Wajib" & $1(14.28)$ \\
\hline BPJS Jamkesmas" & $1(14.28)$ \\
\hline
\end{tabular}

\section{Creatinine serum value differential test}

Analysis of creatinine serum value before the first chemotherapy and after the sixth chemotherapy was administered to determine the difference of creatinine serum value before and after the six series of chemotherapy. The difference of creatinine serum value before and after paclitaxel-cisplatin chemotherapy will be deemed as meaningful if the final value reaches ${ }^{*} \mathrm{p}<0.05$. Meaningful value of the increased creatinine serum after paclitaxel-cisplatin chemotherapy will be used as the indicator of kidney dysfunction side effect.

To determine the range of data distribution, normalized test was conducted to the value of creatinine serum before the first series of chemotherapy and after the sixth series of paclitaxel-cisplatin chemotherapy, using Shapiro-Wilk method for the first series. The data of creatinine serum level before the first series of chemotherapy have a normal distribution. Meanwhile, the level of creatinine serum before the sixth series of chemotherapy has abnormal distribution; therefore, it has to be analyzed with Wilcoxon test. The results of the difference of creatinine serum value before the first series of chemotherapy and after the sixth series of paclitaxel-cisplatin chemotherapy with Wilcoxon test are shown in Table 2 .

Based on the analytical results shown in Table 2, there is no meaningful difference of creatinine serum value before the chemotherapy series I and after paclitaxel-cisplatin chemotherapy series VI. The median value shows that there is a decrease of creatinine serum level after paclitaxelcisplatin chemotherapy series VI although it is not meaningful (*p $>0.05)$

BUN value differential test

Data of BUN value were tested with Shapiro-Wilk normalized test to see the data distribution. Its value before the first chemotherapy series has normal distribution. Meanwhile, its value after the sixth chemotherapy series has abnormal distribution; therefore, it has to be analyzed with Wilcoxon test. The results of the difference of creatinine BUN value before the first chemotherapy series and after the sixth series of paclitaxelcisplatin chemotherapy with Wilcoxon test are shown in Table 3.

Based on analytical results of Table 3, there is no meaningful difference of BUN value before the chemotherapy series I and after paclitaxelcisplatin chemotherapy series VI. The mean value shows that there is an increase of BUN value after paclitaxel-cisplatin chemotherapy series VI although it is still within the normal range and not meaningful $(* \mathrm{p}>0.05)$.

\section{DISCUSSION}

\section{Patients' characteristics}

From Table 1, it could be deduced that all of the cervical cancer patients are all above 30 years old. This is in align with literature sources that explain about how cervical cancer develops in those who are in their 30 s or more [4]. Nevertheless, it could also be diagnosed in female populations who are in their 20s and teens [5].

If linked to marital age, it could be inferred that those who have their first coitus before reaching the 20 s has a risk of infecting cervical cancer. HPV infection as the most common cause of cervical cancer would be identified in between 18-30 years of age which is a few years after the first coitus took place [4].

Table 2: Analytical results of creatinine serum value difference before the first series of chemotherapy and after the sixth series of chemotherapy with Wilcoxon test

\begin{tabular}{lllll}
\hline Chemotherapy & N & Creatinine serum & & p \\
\cline { 3 - 4 } & & Median (ng/L) & Minimum (ng/L) & Maximum (ng/L) \\
\hline Before chemotherapy I & 7 & 0.800 & 0.6 & 1.1 \\
After chemotherapy VI & 7 & 0.700 & 0.52 & 0.600 \\
\hline
\end{tabular}

$\mathrm{N}$ : Sample's quantity, P: Level of meaningfulness. if $\mathrm{p}<0.05$, the difference is meaningful 
Table 3: Analytical results of BUN value difference before the first series of chemotherapy and after the sixth series of chemotherapy with Wilcoxon test

\begin{tabular}{lllll}
\hline Chemotherapy & N & BUN & p \\
\cline { 3 - 4 } & & Median (ng/L) & Minimum (ng/L) & Maximum (ng/L) \\
\hline Before chemotherapy I & 7 & 10.00 & 9.00 & 16.00 \\
After Chemotherapy VI & 7 & 13.00 & 10.00 & 26.00 \\
\hline
\end{tabular}

$\mathrm{N}$ : Sample's quantity, p: Level of meaningfulness, BUN: Blood urea nitrogen. if $\mathrm{p}<0.05$, the difference is meaningful

If observed from educational level, occupational status, and area of origin, most patients have not received adequate information about both the risk and precautionary actions in preventing cervical cancer. This means that more educational programs are necessary in order to increase the awareness about the danger of cervical cancer.

All the research participants were all in stadium IIIB. All of them started their treatment at Obstetrics and Gynecology Clinics of Sanglah GH after been diagnosed at stadium IIIB. This might occur due to the fact that there were no specific symptoms during the early stages of HPV virus infection. Patients started their treatment late after experiencing symptoms such as bleeding and continuous leukorrhea which were indeed developed in later stages. Therefore, early preventive actions of cervical cancer have to be socialized to communities so that successful cervical cancer safeguards could be achieved.

The whole research patients were using Jaminan Kesehatan Nasional (JKN), one of the Indonesia's government health insurance programs. From the data, all the patients in this research were using BPJS Kesehatan through JKN program, either participant paid their own premi or premi paid by the government for less-affluent people. Social Health Insurance is health financing system in a country where revenue typically comes from membership contributions, employer contributions, government subsidies and interest payments on any accumulated funds (Ole et al., 2010). The concept of social health insurance is applied by JKN. The main principle of social health insurance is to prevent households not to fall into poverty because they have to pay the cost of expensive medical treatment [7]. This program was very helpful for the patients who were having their treatments since they are costly.

Chemotherapies would cause side effect such as toxicity. Kidney is one of the organs that could be used in monitoring the toxic implication caused by chemotherapies. Cytotoxic medicine is commonly secreted through kidney, whereas the parameters to determine kidney function are the value of BUN and creatinine serum [8].

\section{Creatinine serum value differential test}

The examination of blood creatinine could be utilized to determine glomerulus' filtration capacity through creatinine clearance test. The level of blood creatinine could also provide the information about the severity level of kidney dysfunction. The value would be higher in deteriorating kidney function [9].

The normal value of creatinine serum according to Sanglah GH Standard Operational Procedure is $0.50-0.90 \mathrm{mg} / \mathrm{dL}$. In this research, the analytical results of Table 2 show that there is no significant increase in creatinine serum value before chemotherapy series I and after chemotherapy series VI $\left({ }^{*} p>0.05\right)$. Six out of the seven patients in this research showed stable creatinine serum value within normal range after the six series of paclitaxel-cisplatin chemotherapy. This is in accordance to the research of Kidera et al. (2014) which stated that there is no significant correlation between cisplatin chemotherapy and kidney's toxicity in which the value is $\mathrm{p}=0.373\left({ }^{*} \mathrm{p}>0.05\right)$. Another research in six squamous cell cervical cancer stadium IIB-IIIB cases using carboplatin-paclitaxel regimen also does not show significant difference toward creatinine serum value after 3 series of chemotherapy $(* \mathrm{p}>0.05)$ [11]. However, this is in contrast to research conducted by Arankumar et al., (2012) in which the value of creatinine serum increased significantly from BUN value after undergoing cisplatin chemotherapy. This might indicate the possibility of severe nephrotoxicity [12]. The contrasting result obtained by this research compared to other literature resources might be triggered by the lack of sufficient samples to provide significant statistics. Meanwhile, the usage of paclitaxel tends to cause myelosuppression instead of deteriorating kidney function [13].

One out of seven patients in this research experienced the increase in creatinine serum value beyond the normal value. The creatinine serum value of this patient before the chemotherapy Series I was $0.8 \mathrm{mg} / \mathrm{dL}$ and it increased 2.7 times to $2.19 \mathrm{mg} / \mathrm{dL}$. The increase of creatinine serum value might indicate the occurrence of the patient's deteriorating kidney function in excreting body's waste. This condition might be the result of cisplatin's side effect. One of them is nephrotoxicity that may lead to kidney failure. Cisplatin nephrotoxicity works by accumulating cisplatin in kidney cells which will then trigger the apoptosis of the cells [2]. The existence of patient with deteriorating kidney function by cisplatin chemotherapy shows the importance of assessing individual patient's response toward chemotherapy. If unwanted response such as the increase of creatinine serum value beyond normal value takes place, it is advisable to adjust the chemotherapy dosage in accordance to the patient's GFR value [14].

That is why, it is necessary to keep tabs on creatinine serum value before chemotherapy, during chemotherapy, and after chemotherapy so that the risk of unwanted incidents such as severe kidney failure could be prevented. This would in return guarantee the safety of patients from side effects that could further exacerbate the life quality of cervical cancer patients

\section{BUN value differential test}

One of the kidney essential functions is to eliminate potential toxic substances such as urea from our bodies. In case of deteriorating kidney function, the BUN value would increase. BUN test, which measures urea nitrogen, is utilized as the index indicator of glomerulus function in producing and excreting urea. Consequently, BUN measurement would be the indicator of kidney function [3].

BUN value measurement would be administered before and after every series of chemotherapy. Analysis of BUN value before and after the first series of chemotherapy until the sixth series of chemotherapy would be administered to determine the difference of BUN value in every series of chemotherapy. Likewise, the analysis of BUN value before the first chemotherapy and after the sixth chemotherapy would also be administered to determine the difference of BUN value before and after the six series of chemotherapy. The difference of BUN value before and after paclitaxel-cisplatin chemotherapy would be considered as meaningful if the value is $* p<0.05$. The increase of BUN value after paclitaxel-cisplatin chemotherapy would be the indicator of kidney dysfunction side effect.

Referral normal BUN value according to Sanglah GH Standard Operational Procedure is $8.00-23.00 \mathrm{mg} / \mathrm{dL}$. BUN value is not only affected by kidney function. Another factor contributing to the change of BUN value is protein intake, which is related to how urea is the waste product of protein metabolism. Thus, the level of patients' protein intake would also affect their BUN value. Besides that, BUN value is also affected by liver because liver is responsible for the conversion of amino acid into urea [3]. 
The level of BUN before chemotherapy I and after chemotherapy VI based on Table 3 of this research shows no significant difference statistically. This is in concord to the research of Arunkumar et al. (2012) that stated out of 18 patients who underwent cisplatin chemotherapy with a dosage of $40-50 \mathrm{mg} / \mathrm{m}^{2}$ for 5 series showed no significant difference in BUN value before and after 5 series of chemotherapy $\left({ }^{*} p=0.292\right)$ [12]. On the other hand, research conducted by Tazcan et al. (2013) involving 52 cancer patients that have undergone platinum-based chemotherapy shows a significant increase in BUN value $(\mathrm{p}<0.05)$ after going through cisplatin chemotherapy (Tazcan et al., 2013). This contrast might be due to the difference of patients' number involved in the research and thus affecting the significant result

On this research, there was one patient who experienced the increase of BUN value beyond the normal value. The patient's BUN level which was $9.00 \mathrm{mg} / \mathrm{dL}$ before chemotherapy series I has increased to $26.00 \mathrm{mg} / \mathrm{dL}$ after going through 6 chemotherapy sessions. The increase of BUN value beyond normal value might indicate the kidney's deteriorating capacity in excreting body's waste. The patient's deteriorationg kidney function might be the result of adverse drug reaction caused by the usage of cisplatin. According to Miller et al., (2010) platinum content in cisplatin plays a role in inducing nephrotoxicity as a consequence of the glomerular damage [2]. Since the possibility for patients to suffer from deteriorating kidney function due to cisplatin chemotherapy exists, it is necessary to observe every patient's response towards chemotherapy. Adjustment of chemotherapy dosage in accordance to patient's GFR value might be considered if cisplatin chemotherapy has led to the deterioration of kidney function.

The fact that some patients suffered from deteriorating kidney function after undergoing cisplatin chemotherapy procedure shows that it is essential to determine every patient's response toward chemotherapy. It is vital to accommodate chemotherapy dosage according to each patient's GFR value in case of the occurrence of symptom like the increase of BUN value beyond the normal one [14].

Therefore, it's advisable to keep track on BUN value before, after, and during chemotherapy procedure to avoid negative outcome like severe kidney failure. By applying this, the risk of cervical cancer patients suffering from unnecessary side effects that could potentially worsen their life quality would be minimized.

\section{CONCLUSION}

There is no significant difference in both BUN value and creatinine serum value before chemotherapy series I and after paclitaxel-cisplatin chemotherapy series VI in squamous cell cervical cancer patients stadium IIB-IIIB at Sanglah GH.

\section{REFERENCES}

1. Colleoni M, Litman HJ, Castiglione-Gertsch M, Sauerbrei W, Gelber RD, Bonetti M, et al. Duration of adjuvant chemotherapy for breast cancer:
A joint analysis of two randomised trials investigating three versus six courses of CMF. Br J Cancer 2002;86:1705-14. Available from: https:// www.ncbi.nlm.nih.gov/pmc/articles/PMC2375405.

2. Miller RP, Tadagavadi RK, Ramesh G, Reeves WB. Mechanisms of Cisplatin nephrotoxicity. Toxins (Basel) 2010;2(11):2490-518.

3. Duong CD, Loh JY. Laboratory monitoring in oncology. J Oncol Pharm Pract 2006;12(4):223-36

4. Lasut E, Rarung M, Suparman E. The Characteristics of Cervical Cancer Patients Prof. Dr. R. D . Kandou BLU General Hospital. J Clin 2015;3(1):83-6. Available from: http:/www.ejournal.unsrat.ac.id/ index.php/ebiomedik/article/view/4600.

5. Spencer JV. Cervical Cancer. USA: Infobase Publishing; 2007. p. 10-4. Available from: https://www.books.google.co.id/books?id= c1gaj5skpwgc\&pg $=$ pa4\&lpg $=$ pa $4 \& d q=$ spencer,+ juliet $+\mathrm{v} .+$ cervical + cancer\&source $=$ bl\&ots $=$ auq $8^{\text {st }} \mathrm{dxts} \&$ sig $\quad=$ qcmcfucdpdsrdeusuhlf $9 y 7$ rufq $\&$ hl $=\mathrm{id} \& \mathrm{sa}=\mathrm{x} \&$ ved $=0$ ahuk ewivgne8i_3pahwipi8 khvpdcl8q6aeiitab\# $\mathrm{v}=$ onepage $\& \mathrm{q}=$ spencer $\% 2 \mathrm{c} \% 20 \mathrm{juliet} \% 20 \mathrm{v} . \% 20$ cervical $\% 20$ cancer\&f $=$ false

6. Ole D, Guy C, David E. World Health Report. 2010. Available from: http://www.who.int/healthsystems/topics/financing/healthreport/ 26_10Q.pdf.

7. Thabrany, H. Jaminan Kesehatan Nasional. Edisi Kedua. Jakarta: PT Raja Grafindo Persada; 2015.

8. Departemen Kesehatan Republik Indonesia. Pedoman Intepretasi Data Klinik. Jakarta: Departemen Kesehatan Republik Indonesia; 2011.

9. Setyaningsih A, Puspita D, Rosyidi MI. The Difference of Urea and Creatinine Level on Patients Undergoing Hemodialysis with both New Fibered Hollow and Reused Fibered Hollow at Ungaran District Hospital. J Keperawatan Med Bedah 2013;1(2):15-24. Available from:http://www.jurnal.unimus.ac.id/index.php/JKMB/article/ view/937.

10. Kidera Y, Kawakami H, Sakiyama T, Okamoto K, Tanaka K, Takeda M, et al. Risk factors for cisplatin-induced nephrotoxicity and potential of magnesium supplementation for renal protection. PLoS One 2014;9(7):e101902. Available from:http://www.journals.plos.org/ plosone/article?id=10.1371/journal.pone.0101902.

11. Noviyani R, Ketut S, Dewi AAWP, Rasmaya N, Tunas IK, Budiana ING. Evaluation of Blood Urea Nitrogen and Creatinine Serum in Squamous Cell Cervical Cancer Patients Stadium IIB-IIIB who Underwent Paclitaxel-Carboplatin Chemotherapy. Indonesian Journal of Clinical Pharmacy Juni 2014;3(2):55-60. Available from: ijcp.or.od/ achives/2014/3/2/IJCP-120189.html.

12. Arunkumar PA, Viswanatha GL, Radheshyam N, Mukund $\mathrm{H}$, Belliyappa MS. Science behinds cisplatin-induced nephrotoxicity $\mathrm{n}$ humans: A clinical study. Asian Pac J Trop Biomed 2012;2(8):640-4. Available from: https://www.ncbi.nlm.nih.gov/pmc/articles/ PMC3609353.

13. Lacy CF, Armstrong LL, Goldman PM, Lance LL. Drug Information Handbook. 20 ${ }^{\text {th }}$ ed. United States: Lexi-Comp Incorporated; 2011. p. 290-3, 1301

14. Ashley C, dan Currie A. The Renal Drug Handbook. Edisi ketiga. New York: Radcliffe Publishing; 2009

15. Tazcan S, Izzettin FV, Sancar M, Yumuk MF, Turhal S. Nephrotoxicity Evaluation in Outpatients Treated with Cisplatin-Based Chemotherapy using a short hydration method. Pharmacology \& Pharmacy 2013; 4: p. 296-302. Available from: http://file.scirp.org/pdf/ PP_2013053113423408.pdf 